\title{
Nutzen bestätigt
}

Für Patienten mit chronischer lymphatischer Leukämie (CLL) liegt jetzt erstmals ein umfassender Prognose-Score vor. Der Index, der sich aus acht klinischen, biologischen und molekularen Markern zusammensetzt, war im Praxistest herkömmlichen Modellen deutlich überlegen.

Als Grundlage für die Diagnose und Stadieneinteilung der chronischen lymphatischen Leukämie (CLL) dient gegenwärtig das Klassifikationssystem nach Rai und Binet. Dieses vor etwa 30 Jahren entwickelte Modell beruht auf konventionellen Parametern wie Differenzialblutbild und körperlicher Untersuchung und lässt sowohl die hohe Variabilität der CLL als auch die Vielzahl der mittlerweile bekannten biologischen Charakteristika auf zellulärer Ebene außer Acht.
Die Studiengruppe um Natali Pflug von der Universität Köln hat nun insgesamt 23 Marker identifiziert, die prognostisch relevant sein könnten, sowohl klinische als auch biologische und molekulargenetische.

\section{Acht unabhängige Prädiktoren}

Von den 23 Parametern stellten sich acht als unabhängige Prädiktoren für das Gesamtüberleben heraus: Geschlecht, Alter, ECOG-Status sowie die chromosomalen Mutationen del(17p) und del(11q), der IgHV-Mutationsstatus, die Serum-Thymidinkinase (s-TK) und das Serum- $\beta 2$-Mikroglobulin.

Diese packte das Team in einen zusammengesetzten Prognose-Score, aus dem es vier Risikokategorien ableitete: niedriges Risiko (0-2 Punkte), mittleres Risiko (3-5), hohes Risiko (6-10) und sehr hohes Risiko (11-14). Die 5-Jahres-Gesamtüberlebensraten lagen zwischen 95,2 (niedrigstes Risiko) und 18,7\% (höchstes Risiko).

Die Forscher errechneten für das neue Prognosemodell einen Vorhersagewert von $\mathrm{c}=0,75$ (C-Statistik). Nach Pflug und Kollegen ist damit die Schwelle, die den prognostischen Nutzen im Einzelfall definiert, deutlich überschritten (der Grenzwert liegt bei 0,70; ein Wert von c $=1$ entspricht einer perfekten Diskriminierung). Zum Vergleich: Die Staging-Systeme nach Rai und Binet zeigen eine C-Statistik von lediglich 0,56 bzw. 0,58.
Quelle: springermedizin.de 